\title{
Evaluation of the Impact of Iron Deficiency Anemia during Pregnancy on Hospital Admission and Utilization of Hospital Resources in Latifa Women and Children Hospital, Dubai, UAE
}

\author{
Nighat Aftab ${ }^{a, b}$ Saima Faraz ${ }^{a, b}$ Komal Hazaric Asma Fahad ${ }^{a}$ \\ Nadia AISawalhee ${ }^{a, b} \quad$ Amal AlQedrah ${ }^{a}$ Shazia Naqvia,b Litty Paulose ${ }^{a, b}$ \\ Widad Abdelkareem ${ }^{c}$ Taghrid EL Gergawi ${ }^{\text {b, c }}$ \\ aDepartment of Obstetrics and Gynecology, Latifa Women and Children Hospital, Dubai, UAE; bepartment of \\ Gynecology and Obstetrics, Dubai Medical College, Dubai, UAE; 'Department of Internal Medicine, Latifa Women \\ and Children Hospital, Dubai, UAE
}

\section{Keywords}

Maternal-fetal outcomes · Anti-anemic · Oral liposomal iron

\begin{abstract}
Introduction: Iron deficiency anemia (IDA) is endemic among pregnant females worldwide. Liposomal iron preparation is a novel therapy for treating IDA in pregnant females. There is a lack of research on cost-effect and comparison between various new iron preparations as liposomal and intravenous (IV) iron supplements in the international literature. Objective: The objective of this study was to evaluate the cost-effect and maternal-fetal outcome of IDA during pregnancy in Latifa Women and Children Hospital, Dubai, UAE. Design: The study was a quasi-experimental study. Settings: Settings include tertiary-care hospital settings affiliated with academic center in UAE. Patients and Methods: A total of 226 pregnant women were inducted in the study who were controlled in terms of age, BMI, baseline hemoglobin $(\mathrm{Hb})$, severity of anemia, and ferritin levels. There were 116 patients who received oral liposomal iron pyrophosphate and 110 patients received IV iron saccharate complex for 4 weeks.
\end{abstract}

The overall cost-effect and maternal-fetal outcomes were compared in 2 groups. Main Outcomes Measured: The main outcomes measured the cost-effect of liposomal and IV iron therapy, and the 2 treatments were compared in terms of maternal and fetal outcomes. Result: The subjects were matched for age and body mass index and showed that the patients in the IV group were more symptomatic than those in the oral group ( 18.1 vs. $31.9 \% p$ value $<0.01$ ). There was no statistically significant difference among women from different nationalities living in UAE ( $p$ value 0.079 ). There were 98 (84.4\%) patients in the oral group and 99 (90\%) patients in the IV group who achieved the desired $\mathrm{Hb}$ levels after 1 month of treatment ( $p$ value $=0.878$ ). Moreover, the side effects were also comparable in both groups (1.72 vs. $1.82 \%$ $p$ value $=0.56$ ). The incremental cost-effect ratio for IV iron was USD 108,633/rise to desired Hb. Conclusion: Liposomal iron preparations may be cost-effective and have fewer side effects than IV iron. In terms of outcome, the maternal and fetal variables are comparable in liposomal and IV groups.

(C) 2021 The Author(s).

Published by S. Karger AG, Basel karger@karger.com www.karger.com/dmj

Karger ${ }^{\prime \prime} \div$

BOPEN ACCESS
(C) 2021 The Author(s)

Published by S. Karger AG, Basel

This is an Open Access article licensed under the Creative Common Attribution-NonCommercial-4.0 International License (CC BY-NC) (http://www.karger.com/Services/OpenAccessLicense), applicable to the online version of the article only. Usage and distribution for commercial purposes requires written permission.
Correspondence to:

Saima Faraz, saimafaraz42@gmail.com 


\section{Introduction}

Iron deficiency anemia (IDA) is the most prevalent nutritional deficiency disease during pregnancy all over the world. It is endemic in developing countries where approximately $50 \%$ of women have iron deficiency during childbearing age where there can be many causes like nutritional deficiency, worm infestation, malaria, and thalassemia [1]. Whereas in the western world, the disease is less common with $24 \%$ of women having anemia during pregnancy and in UAE its prevalence is $28 \%$ [2]. The stark difference can be due to better surveillance and diet. There is a lot of debate regarding the cut off limit of hemoglobin $(\mathrm{Hb})$ in order to declare a person anemic especially during pregnancy. The World Health Organization considers a pregnant female anemic with $\mathrm{Hb}<11 \mathrm{~g} /$ $\mathrm{dL}$ in the first trimester or $<10.5 \mathrm{~g} / \mathrm{dL}$ in the second trimester or $<10 \mathrm{~g} / \mathrm{dL}$ in the third trimester [3]. It is further classified as mild (Hb 10-10.9 g/dL), moderate (Hb 7-9.9 $\mathrm{g} / \mathrm{dL})$, severe $(\mathrm{Hb} 4-6.9 \mathrm{~g} / \mathrm{dL})$, and very severe $(\mathrm{Hb}<4 \mathrm{~g} /$ $\mathrm{dL}$ ) disease [4].

Pregnancy is a high metabolic state wherein the body requires extra nutrients, vitamins, and elemental iron. It is estimated that $1,000 \mathrm{mg}$ of iron is lost from mother during pregnancy and lactation [3]. Since most of the Asian women in child bearing age start pregnancy with depleted stores of iron, the outcome is manifested in the form of anemia, which can have adverse implications for both mother and child [5]. Maternal anemia is associated with high risks of abortion, infection, postpartum hemorrhage, depression, and even death [3,6]. Likewise, mothers with low $\mathrm{Hb}$ levels have higher odds of preterm labor, low birth weight, and perinatal death [7]. Children born to anemic mothers are shown to have poor cognitive functions and mental impairment [8].

The antenatal management of IDA is crucial and involves 3 basic steps. This includes dietary modification of iron-rich nutrients, iron supplementation therapy, and general awareness [2]. Oral iron is the preferred method of replenishing reserves because of low cost and safety. However, they are shown to be associated with adverse effects and slow rise in Hb levels. However, a new liposomal formulation containing iron pyrophosphate has been shown to mitigate the adverse effects while simultaneously increasing iron absorption [9]. Intravenous (IV) iron is administered in cases who do not tolerate oral preparations, and iron sucrose is considered to be safest and reliable. Both oral and IV iron supplements may reduce the risk of peripartum blood transfusions [10]. There is a lack of comparison between the novel liposomal iron supple-

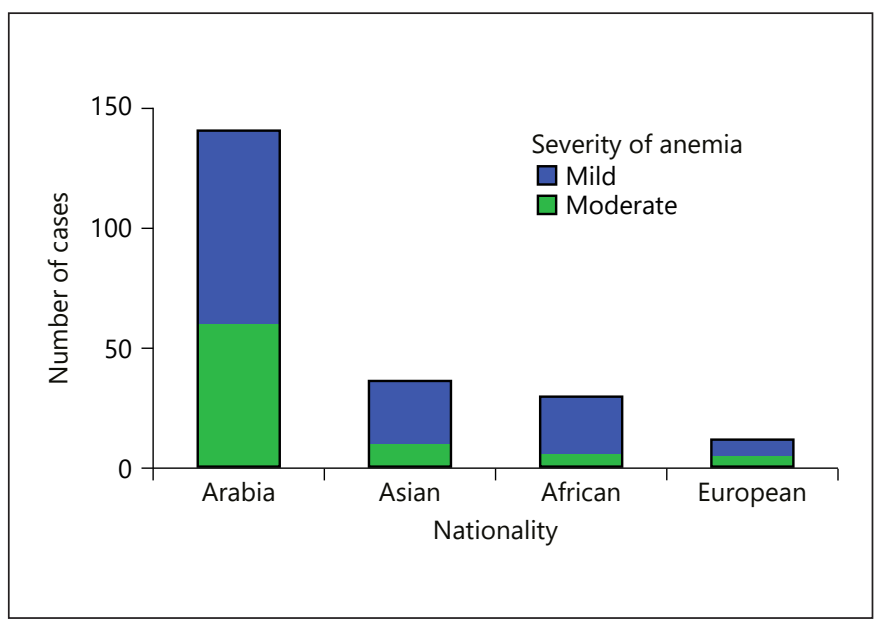

Fig. 1. Distribution of anemia in different nationalities.

ments and IV iron preparations $[9,11]$. The aim of this study was to evaluate the effectiveness of various iron replacement therapies during pregnancy in a multicultural and multiethnic society in terms of cost and utilization of resources. The secondary objective was to evaluate the overall maternal-fetal outcome with the use of iron therapy.

\section{Materials and Methods}

This was a prospective observational study conducted at Latifa Hospital, Dubai Health Authority (Dubai, UAE). Prior approval of the Ethical Committee was obtained, and all interventions were in accordance with set guidelines. Informed written consent was taken for all the cases. A total of 226 pregnant women were inducted in this study. The sampling was done in a consecutive nonrandom manner. All the booked and non-booked pregnant patients between the age of 18 and 46 years diagnosed with mild to moderate anemia and delivered from 1 January 2016 to 31 December 2016 having $\mathrm{Hb}<11.0 \mathrm{~g} / \mathrm{dL}$ in the first trimester or $<10.5 \mathrm{~g} / \mathrm{dL}$ in the second trimester or $<10 \mathrm{~g} / \mathrm{dL}$ in the third trimester and ferritin $<30$ $\mu \mathrm{g} / \mathrm{L}$ were included in the study. The patients who had previously been taking iron supplements, having hemoglobinopathies as thalassemia trait, severe anemia or anemia due to other causes, history of severe allergic reactions to iron, asthma, and malignancy were excluded. Moreover, patients who had some active infection, renal, or hepatic dysfunctions were also excluded.

All the patients who reported in obstetric OPD of Latifa Hospital, Dubai, were screened for anemia by Hb levels. If found to be anemic, the patients were counseled about the disease in detail, and written consent was obtained and then further tests were conducted, namely, serum ferritin and $\mathrm{Hb}$ electrophoresis. The patients were allotted groups in a consecutive manner based on their personal preference after they were briefed about both drugs and the administration pattern. The oral group was required to take lipo- 
Table 1. Maternal characteristics of oral and IV groups $(n=226)$

\begin{tabular}{|c|c|c|c|c|}
\hline $\begin{array}{l}\text { S. } \\
\text { No. }\end{array}$ & Variable & $\begin{array}{l}\text { Oral group } \\
(N=116)\end{array}$ & $\begin{array}{l}\text { IV group } \\
(N=110)\end{array}$ & $p$ value \\
\hline 1 & Age (SD) & $32.34 \pm 5.73$ & $31.62 \pm 5.938$ & 0.35 \\
\hline 2 & BMI (SD) & $29.7 \pm 4.9$ & $29.8 \pm 5.5$ & 0.86 \\
\hline 3 & $\begin{array}{l}\text { Nationality, } n(\%) \\
\text { Arabian } \\
\text { Asian } \\
\text { African } \\
\text { European }\end{array}$ & $\begin{array}{c}81(69.8) \\
12(10.3) \\
17(14.7) \\
6(5.2)\end{array}$ & $\begin{array}{c}65(59.1) \\
25(22.7) \\
13(11.8) \\
7(6.4)\end{array}$ & 0.08 \\
\hline 4 & $\begin{array}{l}\text { Parity, } n(\%) \\
\text { Nulliparous } \\
\text { Having } 2-4 \text { children } \\
\geq 5 \text { children }\end{array}$ & $\begin{array}{c}4(3.4) \\
91(78.4) \\
21(18.1)\end{array}$ & $\begin{array}{c}5(4.5) \\
91(82.7) \\
14(12.7) \\
\end{array}$ & 0.51 \\
\hline 5 & $\begin{array}{l}\text { Gestational age at diagnosis, } n(\%) \\
\text { First trimester } \\
\text { Second trimester } \\
\text { Third trimester }\end{array}$ & $\begin{array}{l}12(10.3) \\
55(47.4) \\
49(42.2)\end{array}$ & $\begin{array}{l}17(15.5) \\
54(49.1) \\
39(35.4)\end{array}$ & 0.389 \\
\hline 6 & Symptomatic, $n(\%)$ & $21(18.1)$ & $37(31.9)$ & 0.008 \\
\hline 7 & $\begin{array}{l}\text { Severity of anemia at } \\
\text { time of diagnosis, } n(\%) \\
\text { Mild } \\
\text { Moderate }\end{array}$ & $\begin{array}{l}76(65.5) \\
40(34.5)\end{array}$ & $\begin{array}{l}61(55.5) \\
49(44.5)\end{array}$ & 0.079 \\
\hline 8 & Baseline $\mathrm{Hb}$ & $9.85 \pm 0.77$ & $9.68 \pm 0.71$ & 0.070 \\
\hline 9 & Serum ferritin & $16.08 \pm 8.1$ & $14.21 \pm 8.1$ & 0.085 \\
\hline
\end{tabular}

$\mathrm{Hb}$, hemoglobin. somal iron tablet twice daily (elemental iron of $30 \mathrm{mg}$ ) for 4 weeks. The IV group was given iron (III) hydroxide saccharate complex, and the dose was evaluated by formula: weight in $\mathrm{kg} \times$ (desired $\mathrm{Hb}$ - patient $\mathrm{Hb}) \times 0.24+500 \mathrm{mg}$. The desired dose was rounded off to the nearest multiple of 100 . It was then administered in the form of infusion through peripheral cannula with a maximum dose of $200 \mathrm{mg}$ at any time diluted in $200 \mathrm{~mL}$ of $0.9 \% \mathrm{NaCl}$, which was given over $30 \mathrm{~min}$. There were a total of 6-8 doses given over 4 weeks (twice a week). The first dose was given as inpatient or outpatient. All the precautions for possible allergic reactions and gastrointestinal upset were taken during administration. Patients were closely monitored for $12 \mathrm{~h}$ for hypersensitivity and then rest were given at a peripheral health center.

The demographic data collected in data sheet were age, nationality, body mass index, gestational age at diagnosis, maternal $\mathrm{Hb}$ at the time of diagnosis, severity of anemia based on WHO classification, parity, and patient education. The primary maternal outcome measured was $\mathrm{Hb}$ at 4 weeks, development of preeclampsia, preterm delivery, mode of delivery, postpartum hemorrhage, infection, hospital admission days, and blood transfusions. The primary fetal outcomes were birth weight, APGAR score at delivery, NICU admissions, and still births. The data were analyzed using Statistical Package for the Social Sciences version 21. The mean and standard deviation were calculated for age, $\mathrm{Hb}, \mathrm{BMI}$, and serum ferritin levels. These quantitative variables were compared by independent $t$ test. Qualitative variables were representative in the form of percentages. The $\chi^{2}$ test was applied to calculate the $p$ value taking the value $<0.05$ as significant. Logistic and multinomial regression models were used to ascertain any association. To determine the cost-effect relation, the incremental cost-effect ratio (ICER) was calculated by the formula (total $\operatorname{cost}_{\text {IV }}$ - total cost $_{\text {oral }}$ )/ (proportion of cases reaching desired $\mathrm{Hb}_{\mathrm{IV}}$ - proportion of cases reaching desired $\mathrm{Hb}_{\text {Oral }}$ ).

\section{Results}

A total of 226 females were part of the study. The patients were divided into 2 groups based on the treatment they were taking. There were $116(51.33 \%)$ participants in the group taking oral liposomal iron and 110 (48.67\%) patients in the group taking IV iron supplements. As Dubai is a multicultural and multiethnic society, we had representation of nearly all ethnic groups. Figure 1 shows the general distribution of different nationalities and the severity of anemia in them. There was no statistical difference seen among the races in terms of presence of IDA $(p$ value $=0.08)$. The 
Table 2. Maternal and fetal outcomes in oral and IV groups $(n=226)$

\begin{tabular}{|c|c|c|c|c|c|}
\hline S. No. & Variable & $\begin{array}{l}\text { Oral group } \\
(N=116)\end{array}$ & $\begin{array}{l}\text { IV group } \\
(N=110)\end{array}$ & $p$ value & OR $(95 \% \mathrm{CI})$ \\
\hline \multicolumn{6}{|c|}{ Maternal outcomes } \\
\hline 1 & $\mathrm{Hb}$ after 4 weeks & $10.7(1.5)$ & $10.7(1.0)$ & 0.77 & $1.0(0.8-1.2)$ \\
\hline 2 & $\begin{array}{l}\text { Transfusion during the course } \\
\text { of pregnancy and postpartum }\end{array}$ & $4(\%)$ & $3(\%)$ & 0.75 & $1.2(0.2-5.8)$ \\
\hline 3 & $\begin{array}{l}\text { Gestational age at delivery, } n(\%) \\
<37 \text { weeks }\end{array}$ & $10(8.6)$ & $19(17.3)$ & 0.056 & $0.452(0.200-1.021)$ \\
\hline 4 & $\begin{array}{l}\text { Mode of delivery, } n(\%) \\
\text { Spontaneous } \\
\text { Elective C-section } \\
\text { Emergency C-section }\end{array}$ & $\begin{array}{l}76(65.5) \\
17(14.7) \\
23(19.8)\end{array}$ & $\begin{array}{l}58(52.7) \\
20(18.2) \\
32(29.1)\end{array}$ & 0.137 & $\begin{array}{l}0.649(0.312-1.348) \\
0.549(0.291-1.036)\end{array}$ \\
\hline 5 & Postpartum hemorrhage, $n(\%)$ & $3(2.6)$ & $8(7.27)$ & 0.117 & $0.338(0.087-1.310)$ \\
\hline 6 & Preeclampsia, $n(\%)$ & $2(1.7)$ & $3(2.7)$ & 0.608 & $0.626(0.103-3.818)$ \\
\hline 7 & Infection, $n(\%)$ & $4(3.4)$ & $3(2.7)$ & 0.755 & $1.274(0.279-5.825)$ \\
\hline \multicolumn{6}{|c|}{ Fetal outcomes } \\
\hline 8 & Still births, $n(\%)$ & - & $2(1.8)$ & 0.145 & - \\
\hline 9 & $\begin{array}{l}\text { Birth weight, } n(\%) \\
<2,500 \mathrm{~g}\end{array}$ & $12(10.3)$ & $16(14.5)$ & 0.340 & $0.678(0.305-1.507)$ \\
\hline 10 & APGAR score <7, $n(\%)$ & $5(4.3)$ & $4(3.6)$ & 0.79 & $0.8(0.2-3.2)$ \\
\hline 11 & NICU admission, $n(\%)$ & $5(4.3)$ & $8(7.2)$ & 0.34 & $1.7(0.5-5.5)$ \\
\hline
\end{tabular}

$\mathrm{Hb}$, hemoglobin.

Table 3. Cost-effect analysis between oral and IV groups $(n=226)$

\begin{tabular}{lcr}
\hline & Oral liposomal iron, USD & IV iron saccharate, USD \\
\hline Cost of treatment & 65 & 493 \\
Hospital admission/detention/delivery charges & 1,200 & 3,800 \\
Laboratory charges & 310 & 315 \\
NICU admission & 600 & 1,960 \\
Miscellaneous charges & 3,810 & 5,500 \\
Total cost & 5,985 & 12,068 \\
Incremental cost & 6,083 & 90 \\
Percentage of cases having desired Hb, \% & 84.4 & \\
ICER, USD/Hb & 108,625 &
\end{tabular}

ICER, incremental cost-effect ratio; $\mathrm{Hb}$, hemoglobin.

demographic characteristics of both groups are shown in Table 1 . The mean (SD) age and BMI of all participants were $31.9 \pm 5.8$ years and $29.8 \pm 5.3$, respectively. The baseline characteristics of mothers in oral and IV groups are shown in Table 1. Patients in the IV group were more symptomatic than those in the oral group ( $p$ value $=0.008$ ).
After 4 weeks of treatment, the groups were observed closely during pregnancy, peripartum, and 1 week postpartum period. In the oral group, $2(1.72 \%)$ patients reported having side effects of the therapy, mainly mild gastrointestinal upsets, but they were able to tolerate the treatment. In the IV group, 2 (1.8\%) patients had palpita- 
tions after injection. There was no statistically significant difference between the 2 groups ( $p$ value $=0.56$ ). The maternal and fetal outcomes between both groups are shown in Table 2. Ninety-eight (84.4\%) patients in the oral group and $99(90 \%)$ patients in the IV group achieved the desired $\mathrm{Hb}$ levels after 1 month of treatment ( $p$ value = 0.878 ). In terms of the cost-effect analysis shown in Table 3, IV treatment has an incremental cost of USD 6,083 per case and the ICER of USD 108,625/rise in Hb.

\section{Discussion}

This observational study compared oral liposomal iron pyrophospahte with IV ferous (III) saccharate in terms of cost-effectiveness and maternal-fetal outcome among pregnant women. IDA is rampant among pregnant females, and various strategies have been devised to diminish the problem [12]. It was also noted that symptomatic patients chose IV treatment over oral therapy ( 18.1 vs. $31.9 \% p$ value $<0.01$ ). It is worth mentioning that there was no statistically significant difference among women from different nationalities living in UAE ( $p$ value 0.079 ). Mild to moderate anemia is often well tolerated during pregnancy and diagnosed at the first antenatal visit. Most of our target population had their first antenatal visits during the second and third trimester of pregnancy. The severity of anemia, baseline $\mathrm{Hb}$, and ferritin were comparable in both groups.

There is a lack of published literature on comparison of liposomal iron and IV preparations. Our study demonstrated that oral liposomal iron which contains micronized ferrous pyrophosphate in liposomal microencapsulation has efficacy comparable to IV ferrous saccharate complex after 4 weeks of treatment with $84.4 \%$ of patients achieving desired $\mathrm{Hb}$ in said time. Moreover, the side effects were also comparable in both groups $(1.72$ vs. $1.82 \% p$ value $=0.56)$. The lipid bilayer prevents the interaction between the iron particles and mucosal membrane of gut as well as digestive enzymes [13]. Hence, they are better tolerated than the conventional iron preparations. Moreover, the liposomal iron has better bioavailability than conventional iron regimens. It also does not require any protein carrier in the gut for transport [14]. None of the oral group patients had to be left out owing to side effects of iron supplements. Similarly, a study on palatability of iron preparations showed that liposomal iron had a significant visual analog score when compared with other oral iron supplements (7.6 vs. $2.9 p$ value $<0.01$ ) [15], whereas a study by Fouelifack et al. [16] showed that only $16.4 \%$ of pregnant women were fully compliant to conventional iron sulfate and the main reason for noncompliance was GI side effects in $20 \%$ of cases. Parisi et al. [17] showed that liposomal oral iron containing elemental iron of $28 \mathrm{mg}$ achieved the greatest increase in the mean $\mathrm{Hb}$ as compared to other groups.

It was observed that maternal and fetal outcomes were comparable in both groups. The oral iron group had fewer cases of preterm delivery ( $8.6 \mathrm{vs} .17 .3 \% p$ value $=0.056$ ), emergency C-sections ( 19.8 vs. $29.1 \% p$ value $=0.137$ ), low birth weight $(10.3$ vs. $14.5 \% p$ value $=0.340)$, and NICU admission ( 4.3 vs. $7.2 \% p$ value $=0.34$ ), but the results were statistically insignificant. Parisi et al. [18] showed that the newborns born to mothers taking oral liposomal iron had more mean birth weight than others $(3,479 \pm 587$ vs. $3,092 \pm 469 \mathrm{~g}, p<0.05)$. The exact mechanism of having more weight in newborns in the oral group is not known, but it can be due to better availability of iron to the fetus for hemopoiesis.

It is estimated that around $20 \%$ of patients with mild to moderate anemia require transfusion during delivery and afterward [19]. The total number of patients who were transfused blood in our study was $3 \%$. So, oral and IV supplements may prevent the requirement of transfusion, thus providing overall cost benefit.

The liposomal iron is cost-effective when compared with IV iron. The ICER for IV iron was USD 108,633/rise to desired Hb. This means that as compared to oral iron, an additional cost of USD 108,633 has to be spent for desired rise in $\mathrm{Hb}$. There is a lack of data comparing oral and IV iron in pregnancy. This is high as in the USA, and the threshold for ICER is USD 75,000-100,000 [20].

There are few limitations in our study. Although the study encompassed nearly all nationalities, it was conducted in a single center. Although both the groups were matched in terms of age, BMI, $\mathrm{Hb}$, and serum ferritin, there were still biases. The authors recommend a multicentric randomized control trial to assess the overall effectiveness of liposomal iron preparations.

\section{Conclusion}

Liposomal iron preparations may be cost-effective in terms of increase in $\mathrm{Hb}$ levels at 4 weeks and have fewer side effects than IV iron. The number of transfusions required was also comparable with the IV group. In terms of outcome, the maternal and fetal variables are comparable in liposomal and IV groups. 


\section{Acknowledgement}

The authors are greatly thankful to the Pathology Department for providing all laboratory investigations.

\section{Statement of Ethics}

All procedures followed were in accordance with the ethical standards of the Responsible Committee and with the Helsinki Declaration of 1975, as revised in 2000. Informed consent was obtained from all patients for being included in the study. Subjects (or their parents or guardians) gave their written informed consent and the study protocol was approved by the Dubai Scientific Research Ethics Committee (DSREC), Dubai Health Authority, DSREC-08/2018_04 dated 8 September 2018.

\section{Conflict of Interest Statement}

The authors have no conflicts of interest to disclose.

\section{Funding Sources}

There was no external funding provided for the research.

\section{Author Contributions}

N.A. conceived and designed the research. S.F., K.H., and T.E. did data analysis and manuscript writing. N.A.S. supervised the whole study and editing of the manuscript. A.F., A.Q., S.N., L.P., and W.A. did data collection and compiling international research.

\section{References}

1 Rahmati S, Delpisheh A, Parizad N, Sayehmiri K. Maternal anemia and pregnancy outcomes: a systematic review and meta-analysis. Int J Pediatr. 2016 Aug 1;4(8):3323-42.

2 Ahmed A, Nasir H, Shafiq QA, Naeem B, Ghelani Y, Shaikh RB. The effect of anemia on pregnancy and fetal outcome: GMC hospital, Ajman, UAE. Gulf Med J. 2015;4(S1):S76-82.

3 Gupta A, Gadipudi A. Iron deficiency anaemia in pregnancy: developed versus developing countries. Hematology. 2018 Aug;6(1): 101-9.

4 Nair M, Choudhury MK, Choudhury SS, Kakoty SD, Sarma UC, Webster P, et al. Association between maternal anaemia and pregnancy outcomes: a cohort study in Assam, India. BMJ Glob Health. 2016 Apr 1;1(1):e000026.

5 Baig JA, Jamal MM, Jamal J, Musarrat M. To determine the association of maternal anemia with perinatal outcome in tertiary care hospital. Pak Armed Forces Med J. 2020 Apr 30; 70(2):302-7.

6 Gopinath S, Dhananjaya B, Sreelasya K, Krishna C. Prevalence of anemia in pregnancy and its outcome in rural Tertiary Care Centre in India. Ind J Obstet Gynecol Res. 2018 Jan;5(1):104-8.

7 Lone FW, Qureshi RN, Emmanuel F. Maternal anaemia and its impact on perinatal outcome in a tertiary care hospital in Pakistan. East Mediterr Health J. 2004;10(6):801-7.
8 Koura GK, Ouedraogo S, Le Port A, Watier L, Cottrell G, Guerra J, et al. Anaemia during pregnancy: impact on birth outcome and infant haemoglobin level during the first 18 months of life. Trop Med Int Health. 2012 Mar; 17(17):283-91.

9 Biniwale P, Pal B, Sundari T, Mandrupkar G, Datar N, Khurana AS, et al. Liposomal iron for iron deficiency anemia in women of reproductive age: review of current evidence. Open J Obstet Gynecol. 2018 Sep 11;8(11): 993.

10 Al RA, Unlubilgin E, Kandemir O, Yalvac S, Cakir L, Haberal A. Intravenous versus oral iron for treatment of anemia in pregnancy: a randomized trial. Obstet Gynecol. 2005 Dec 1;106(106):1335-40.

11 Bayoumeu F, Subiran-Buisset C, Baka NE, Legagneur $\mathrm{H}$, Monnier-Barbarino $\mathrm{P}$, Laxenaire MC. Iron therapy in iron deficiency anemia in pregnancy: intravenous route versus oral route. Am J Obstet Gynecol. 2002;186(3): $518-22$.

12 Kaur S. Iron deficiency anemia (IDA): a review. Int J Sci Res. 2016;5:1999-2003.

13 Hussain U, Zia K, Riffat Iqbal MS, Ashraf N. Efficacy of a novel food supplement $\left(\right.$ Ferfer $^{\circledR}$ ) containing microencapsulated iron in liposomal form in female iron deficiency anemia. Cureus. 2019 May;11(5):e4603.

14 Pisani A, Riccio E, Sabbatini M, Andreucci M, Del Rio A, Visciano B. Effect of oral liposomal iron versus intravenous iron for treatment of iron deficiency anaemia in CKD patients: a randomized trial. Nephrol Dial Transplant. 2015;30(4):645-52.
15 Siddiqui AS, Ashraf T, Imran U. Palatability of micro-encapsulated iron pyrophosphate $\left(\right.$ Ferfer $^{\circledR}$ ). Int J Clinical Trials. 2018;5:86-9.

16 Fouelifack FY, Sama JD, Sone CE. Assessment of adherence to iron supplementation among pregnant women in the Yaounde gynaecoobstetric and paediatric hospital. Pan Afr Med J. 2019 Dec 26;34(34):211.

17 Parisi F, Brunetti M, Fusè F, Capriata I, Mandò C, Berti C, et al. Relationship between food intake, iron supplementation, haematochemical state and outcomes in pregnancy, in a cohort of pregnant women in Italy. Woman: the fascination of modern gynecology between health and woman security: upgrades and necessities; 2012 Apr 12-14. Congress Palace, Montecatini Terme, Italy; 2012.

18 Parisi F, Fusè F, Brunetti M, Mazzocco M, Berti C, Cetin I. Effects of different regimens of iron supplementation on iron status and pregnancy outcomes in a cohort of healthy pregnant women: a randomized control trial. J Matern Fetal Neonatal Med. 2017;30:178792.

19 Subramanyam K, Murthy MR. Emergency cesarean section and blood transfusions in patients with severe anemia: our experience. J NTR Univ Health Sci. 2013 Oct 1;2(4):255.

20 Wong G, Howard K, Hodson E, Irving M, Craig JC. An economic evaluation of intravenous versus oral iron supplementation in people on haemodialysis. Nephrol Dial Transplant. 2013 Feb 1;28(28):413-20. 